\title{
EFeito da CompactaçÃo do Solo e do Sulfentrazone sobre a Cultura da Soja em Duas Condições de Água no Solo ${ }^{1}$
}

\author{
Effect of Soil Compaction and Sulfentrazone on Soybean Under Two Soil Moisture Conditions
}

\author{
ZOBIOLE, L.H.S. ${ }^{2,3}$, OLIVEIRA JR., R.S..$^{3,4}$, TORMENA, C.A. ${ }^{3,4}$, CONSTANTIN, J. ${ }^{3,4}$, CAVALIERI, \\ S.D. ${ }^{2,3}$, ALONSO, D.G. ${ }^{3,5}$, BRIGHENTI, A.M. ${ }^{6}$ e CASTRO, C. ${ }^{6}$
}

\begin{abstract}
RESUMO - Estudou-se neste trabalho a atividade do sulfentrazone sobre plantas de soja cultivadas em um Latossolo Vermelho distroférrico com diferentes níveis de compactação. As unidades experimentais foram constituídas por colunas de PVC com altura de 0,25 m e diâmetro interno de $0,145 \mathrm{~m}$, nas quais foram colocadas massas de solo ( $30 \%$ de umidade) suficientes para atingir o nível de compactação desejado. O delineamento experimental adotado foi o inteiramente casualizado, em esquema fatorial $4 \times 2 \times 2$, correspondendo a quatro níveis de compactação do solo $\left(1,0,1,2,1,4\right.$ e $\left.1,5 \mathrm{~g} \mathrm{~cm}^{-3}\right)$, presença ou ausência do herbicida e duas frações de poros preenchidas com água ( 80 e $70 \%$ da porosidade total), com quatro repetições. O sulfentrazone reduziu a área foliar, a formação de nódulos, a massa seca dos nódulos e o acúmulo de nitrogênio na parte aérea. Esses efeitos foram mais acentuados com o aumento da densidade do solo.
\end{abstract}

Palavras-chave: inibidores da Protox, aril triazolinona, manejo do solo.

\begin{abstract}
This experiment aimed to evaluate the activity of sulfentrazone on soybean plants grown in a Typic Haplorthox, under different soil compaction levels. Experimental units were PVC columns $0.25 \mathrm{~m}$ high and with $0.145 \mathrm{~m}$ of internal diameter, in which enough soil mass $130 \%$ moisture) was placed to achieve the desired compaction level. The experimental design was completely randomized, in a $4 \times 2 \times 2$ factorial scheme, corresponding to four compaction levels (1.0, 1.2, 1.4 and $1.5 \mathrm{~g} \mathrm{~cm}^{-3}$ ), presence or absence of herbicide and two soil moistures (80 and $70 \%$ of total porosity filled with water), with four replicates. Sulfentrazone reduced the foliar area, nodule development, nodule dry matter and shoot nitrogen accumulation. Such effects became more pronounced with increased soil compaction.
\end{abstract}

Keywords: Protox inhibitors, aril triazolinone, soil management.

\section{INTRODUÇÃO}

Em sistemas agrícolas, o solo representa o destino final dos herbicidas nele aplicados diretamente ou na parte aérea das plantas. Nesse compartimento, os herbicidas podem ser sorvidos, lixiviados e/ou degradados por meio de processos físicos, químicos e biológicos. Apenas pequena parte desses produtos é absorvida pelas plantas daninhas e cultivadas. A compreensão desses processos é fundamental para a previsão do comportamento dos herbicidas nos mais variados tipos de solo, pois todos esses processos apresentam-se

1 Recebido para publicação em 12.4.2006 e na forma revisada em 21.2.2007.

Parte da dissertação do primeiro autor apresentada para obtenção do título de Mestre em Agronomia, área de concentração em Proteção de Plantas

2 Eng ${ }^{\circ}-$ Agr ${ }^{\circ}$, M.Sc., pós-graduando em Agronomia - UEM; ${ }^{3}$ Bolsista do CNPq; ${ }^{4}$ Professor Associado, Dep. de Agronomia UEM. Av. Colombo, 5790, 87020-900 Maringá-PR, <rsojunior@ uem.br>; ${ }^{5}$ Graduando em Agronomia - UEM, Bolsista de Iniciação Científica CNPq; ${ }^{6}$ Pesquisad or da Embrapa Soja - Londrina-PR. 
amplamente dependentes das características fisicas do tipo de solo considerado e também das condições climáticas locais (Velini, 1992).

O herbicida sulfentrazone foi registrado inicialmente para controle de plantas daninhas na cultura da soja. Atualmente é muito utilizado na cultura da cana-de-açúcar, para controle de tiririca (Alves et al., 2004), embora atualmente possua registro para uso também em outras culturas. Aplicado ao solo, é absorvido pelas raízes e translocado pelo xilema até o ponto de ação, onde, na presença de luz, inibe a enzima protoporfirinogênio oxidase, que atua na biossintese da clorofila, resultando na formação de oxigênio livre. Este, por sua vez, causa a peroxidação de lipídios da membrana celular e, cons eqüentemente, a ruptura desta, levando as plantas suscetiveis à morte. Seu modo de ação é similar ao dos herbicidas do grupo difenil éteres (Duke et al., 1991; Dayan et al., 1997; Wehje et al., 1997).

O sulfentrazone pode ser utilizado em préplantio incorporado ou em pré-emergência, para controle de diversas dicotiledôneas e gramineas (Reddy \& Locke, 1998). Segundo Dirks et al. (2000), deve ser aplicado preferencialmente logo após a semeadura da cultura, pois o uso imediatamente antes ou durante a fase de emergência das plantas de soja aumenta o risco de injúria, quando comparado com aplicações mais precoces, provavelmente devido à maior concentração do herbicida na zona de germinação das sementes (Hulting et al., 2001).

Segundo Inoue et al. (2003), um dos critérios usados para avaliar o risco potencial de lixiviação dos herbicidas é o índice GUS, proposto por Gustafson (1989), o qual é calculado a partir dos valores de meia-vida do composto no solo $\left(\mathrm{t}_{1 / 2}\right)$ e do coeficiente de sorção, normalizado para o teor de carbono orgânico $\left(\mathrm{K}_{\mathrm{oc}}\right)$. Este índice é empírico e classifica os compostos de acordo com sua tendência de lixiviação. Herbicidas com GUS < 1,8 são considerados não passiveis de lixiviação, ao passo que os de índices superiores a 2,8 representam produtos passíveis de lixiviação. Aqueles com valores entre 1,8 e 2,8 são considerados intermediários. Spadotto (2002), estudando métodos para avaliar o potencial de lixiviação de pesticidas, adotou, com base em dados disponiveis na literatura, o valor de $\mathrm{K}_{\mathrm{oc}}=10$ para o sulfentrazone, o que gerou um índice GUS $=6,90$, classificando este herbicida como passivel de lixiviação.

O sulfentrazone é considerado um ácido fraco do ponto de vista de dissociação, com pKa de 6,56. Apresenta, portanto, predominância de carga liquida zero em $\mathrm{pH}$ abaixo de 6,56 e de carga líquida negativa acima deste $\mathrm{pH}$ (Grey et al., 1997, 2000; Reddy \& Locke, 1998). Teoricamente, formas aniônicas e neutras estarão presentes em quantidades semelhantes quando o $\mathrm{pH}$ for igual ao $\mathrm{pKa}$ (Grey et al., 1997).

Grey et al. (1997) estudaram a adsorção do sulfentrazone e a sua mobilidade no solo e constataram que a adsorção desse herbicida foi fortemente influenciada pelo $\mathrm{pH}$ do solo, pois em valores de $\mathrm{pH}$ maiores que seu pKa ocorreu diminuição da adsorção e aumento da concentração do herbicida na solução do solo.

Arruda et al. (2001) avaliaram o efeito de doses de sulfentrazone sobre a nodulação e fixação do nitrogênio na cultura da soja e observaram que a concentração de ureídeos na seiva do xilema decresceu em razão do incremento de doses do herbicida, além da diminuição do número de nódulos e de sua matéria seca, concluindo que o sulfentrazone reduz tanto a formação de nódulos quanto a fixação do $\mathrm{N}_{2}$; esses efeitos são acentuados com o aumento da dose do herbicida.

A compactação do solo é, por definição, a compressão do solo não-saturado, provocando uma reorganização estrutural das partículas e de seus agregados, resultando em aumento da densidade do solo e redução na macroporosidade e, conseqüentemente, na porosidade total (Stone et al., 2002). Is so resulta em restrição ao crescimento da raiz, a qual afeta o crescimento da planta e a produção de biomassa. Entretanto, o efeito da compactação do solo na biomassa da raiz depende do grau de compactação, do teor de água no solo e das propriedades físicas desse solo. Os principais efeitos negativos da compactação do solo são o aumento da resistência mecânica, a redução da aeração e da disponibilidade de água e nutrientes e, conseqüentemente, o decréscimo da produtividade (Goedert et al., 2002). Tormena et al. (2002), em um estudo sobre as propriedades fisicas de um Latossolo Vermelho 
distroférrico, cultivado com mandioca, após dois anos de implantação de diferentes sistemas de preparo do solo, observaram que o sistema de plantio direto (SPD), além de reduzir a porosidade total, muda drasticamente a distribuição do tamanho dos poros, com redução daqueles de maior tamanho. Em relação à microporosidade, os autores observaram aumento no SPD, comparado com o sistema de plantio convencional (SPC), o que se deve ao incremento da densidade do solo no SPD. Isso demonstra que com o aumento da microporosidade a percolação de água no solo é reduzida, sugerindo que possa haver aumento da disponibilidade dos herbicidas aplicados ao solo e, conseqüentemente, da absorção e do potencial de fitointoxicação pelas plantas cultivadas.

Nesse contexto, o objetivo deste trabalho foi avaliar o efeito da compactação do solo na atividade do herbicida sulfentrazone na cultura da soja, conduzida sob duas condições de água no solo.

\section{MATERIAL E MÉTODOS}

O experimento foi realizado em casa de vegetação, durante o período de 20 de agosto a 13 de outubro de 2004. O solo utilizado foi identificado como Latossolo Vermelho nitossólico. Resultados das análises química e granulométrica encontram-se na Tabela 1 .

As amostras dos solos foram coletadas na camada de $0-0,20 \mathrm{~m}$ e passadas em peneira de $0,004 \mathrm{~m}$. O solo foi ensacado e deixado em repouso por 48 horas. Após esse periodo, foram retiradas amostras para cálculo da umidade do solo, por meio do método do anel volumétrico. O solo foi umedecido até $30 \%$ de sua massa seca, procedendo-se à homogeneização do volume de água adicionado ao solo em sacos plásticos. O solo foi deixado em repouso, novamente por 24 horas, antes da operação de compactação.

As unidades experimentais foram constituídas por colunas cilindricas de PVC com altura de $0,25 \mathrm{~m}$ e diâmetro interno de $0,145 \mathrm{~m}$, nas quais o solo foi disposto em camadas de aproximadamente $0,06 \mathrm{~m}$ de espessura. O procedimento para compactação foi adaptado daquele descrito por Mueller et al. (2001), que consiste em compactação de sucessivas camadas de solo no interior do anel, utilizando diferentes niveis de energia, para atingir a densidade do solo desejada. Cada camada foi compactada em decorrência da queda livre de um êmbolo de $3 \mathrm{~kg}$, da altura de 0,48 m, no centro geométrico de um suporte de aço com diâmetro ligeiramente inferior ao do vaso.

O solo foi compactado até a altura de $0,20 \mathrm{~m}$ das colunas e o restante $(0,05 \mathrm{~m})$ preenchido por uma camada de solo com densidade de $1,0 \mathrm{~g} \mathrm{~cm}^{-3}$, considerado não-compactado, e pela adição de $50 \mathrm{~g}$ de palha, para diminuir a evapotranspiração. Os níveis de compactação corresponderam a 2, 6, 14 e 55 impactos por camada de solo, pressão essa exercida pela queda do êmbolo para as densidades de $1,0,1,2,1,4$ e $1,5 \mathrm{~g} \mathrm{~cm}^{-3}$.

Os tratamentos foram combinados em um esquema fatorial ( $4 \times 2 \times 2)$, inteiramente casualizado, sendo os fatores: quatro niveis de compactação $\left(1,0,1,2,1,4\right.$ e $\left.1,5 \mathrm{~g} \mathrm{~cm}^{-3}\right)$, duas frações de poros do solo preenchidas com água (80 e 70\% da porosidade total), com e sem herbicida, com quatro repetições. A fração volumétrica total dos poros do solo, comumente chamada de porosidade total (PT), foi obtida através da fórmula proposta por Prevedello (1996): $\mathrm{PT}=1-\mathrm{Ds} / \mathrm{Dp}$, em que Ds corresponde à densidade do solo e $\mathrm{Dp}$ à densidade de

Tabela 1 - Análises química e granulométrica de amostras de solo, na camada de 0,0-0,20 m, do Centro Tecnológico de Irrigação (CTI) da UEM, Maringá-PR, 2004

\begin{tabular}{|c|c|c|c|c|c|c|c|c|}
\hline \multicolumn{2}{|c|}{$\mathrm{pH}$} & $\mathrm{C}$ & $\mathrm{P}$ & $\mathrm{Al}^{+++}$ & $\mathrm{H}^{+}+\mathrm{Al}^{+++}$ & $\mathrm{Ca}^{++}+\mathrm{Mg}^{++}$ & $\mathrm{Ca}^{++}$ & $\mathrm{K}^{+}$ \\
\hline $\mathrm{CaCl}_{2}$ & $\mathrm{H}_{2} \mathrm{O}$ & $--\mathrm{g} \mathrm{dm}^{-3}--$ & $\mathrm{mg} \mathrm{dm}^{-3}$ & --------- & ---------- & $\mathrm{mol}_{\mathrm{c}} \mathrm{dm}^{-3}-$ & 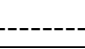 & ----- \\
\hline 5,2 & 6,1 & 15,07 & 9,0 & 0,0 & 4,61 & 8,60 & 5,23 & 0,33 \\
\hline \multicolumn{3}{|c|}{ Areia grossa } & \multicolumn{2}{|c|}{ Areia fina } & \multicolumn{2}{|c|}{ Silte } & \multicolumn{2}{|c|}{ Argila } \\
\hline \multicolumn{9}{|c|}{ 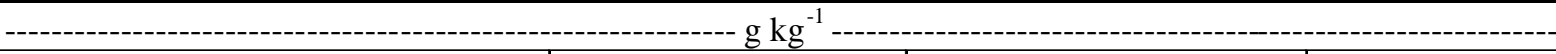 } \\
\hline \multicolumn{3}{|c|}{100} & \multicolumn{2}{|c|}{80} & \multicolumn{2}{|c|}{110} & \multicolumn{2}{|c|}{710} \\
\hline
\end{tabular}


partículas. No solo utilizado neste estudo a densidade de partículas era de $2,93 \mathrm{~g} \mathrm{~cm}^{-3}$.

Após a compactação, foram semeadas seis sementes de soja cv. BRS-133 inoculadas com Bradyrhizobium elkanii, estirpes Semia 587 e Semia 5019, contendo $1 \times 10^{9}$ bactérias $\mathrm{mL}^{-1}$ por coluna, na profundidade de $2 \mathrm{~cm}$. Antes da semeadura as sementes foram tratadas com uma mistura de Carboxin $200 \mathrm{~g} \mathrm{~L}^{-1}$ e Thiram $200 \mathrm{~g} \mathrm{~L}^{-1}$. O sulfentrazone foi aplicado em préemergência da cultura, na dose de $600 \mathrm{~g} \mathrm{ha}^{-1}$, com a barra de pulverização posicionada a $0,50 \mathrm{~m}$ de altura em relação ao nivel da extremidade superior da coluna, utilizando equipamento costal com bicos tipo leque SF110.02, sob pressão constante de $\mathrm{CO}_{2}$ de $2 \mathrm{kgf} \mathrm{cm}^{-2} \mathrm{e}$ volume de calda de $200 \mathrm{~L} \mathrm{ha}^{-1}$. Decorridos sete dias da emergência, realizou-se o desbaste, deixando-se três plantas de soja por coluna.

A manutenção do conteúdo de água no solo (70 e $80 \%$ do volume total de poros), durante a condução do experimento, foi feita mediante pesagem a cada dois dias das colunas e adição de água para repor a que foi evapotranspirada.

Aos 50 dias após a emergência, foram feitas análises da taxa de fotossíntese líquida, utilizando o equipamento Li-Cor 6400, Lincoln, NE, EUA (Portable Photosynthesis System). As avaliações foram feitas entre 12 e 17 horas, escolhendo-se a planta com o estádio vegetativo mais representativo da coluna, fazendo-se as medidas na parte mediana dos folíolos, completamente expandidos, presentes no terço superior das plantas. Aos 51 dias, procedeuse à colheita das plantas, separando a parte aérea da raiz, e à contagem do número de nódulos. Estes, após lavagem com água corrente, foram secos em estufa com circulação forçada de ar a $65-70{ }^{\circ} \mathrm{C}$ até peso constante, quando foram tomados os pesos da matéria seca, por pesagem em balança de precisão.

As medidas da área foliar das plantas foram obtidas por meio de um medidor eletrônico específico (Delta T. Devices), na Embrapa Soja (Londrina, PR), procedendo-se em seguida às análises do teor de nitrogênio no Laboratório de Análise de Solo e Tecido Vegetal - LASTV.

Foram realizadas análises de variância para área foliar, número de nódulos, massa seca dos nódulos e taxa fotossintética das plantas.
Equações de regressão foram ajustadas para todas essas variáveis, e testes de média foram aplicados quando necessário.

\section{RESULTADOS E DISCUSSÃO}

\section{Área foliar}

A área foliar foi afetada pela interação entre os niveis de compactação do solo na presença ou ausência do herbicida.

De modo geral, nas densidades de 1,0 e $1,2 \mathrm{~g} \mathrm{~cm}^{-3}$, a área foliar foi superior às áreas observadas para as densidades de 1,4 ou $1,5 \mathrm{~g} \mathrm{~cm}^{-3}$. Por outro lado, quando se analisa o efeito do teor de umidade (Fpa) sobre a área foliar, apenas no nível de compactação de $1,4 \mathrm{~g} \mathrm{~cm}^{-3}$ houve redução de área foliar com o aumento da disponibilidade de água.

Procópio et al. (2004), em levantamento sobre as características fisiológicas da cultura da soja (cultivar UFV-19), em campo, observaram que as plantas de soja, aos 39 dias após emergência, possuíam média de $302 \mathrm{~cm}^{2}$ de área foliar em densidades do solo propícias ao cultivo da soja, o que se assemelha aos resultados obtidos neste trabalho aos 50 dias após a emergência nas densidades de 1,0 e $1,2 \mathrm{~g} \mathrm{~cm}^{-3}$ (Tabela 2).

Sidiras \& Vieira (1984) observaram que pequena compactação do solo pode propiciar melhor retenção de água e melhores condições de absorção de nutrientes. Queiroz-Voltan et al. (2000) observaram resultados semelhantes aos desses trabalhos, demonstrando que a área foliar diminuiu com o aumento da densidade do solo, a partir da densidade de $1,2 \mathrm{~g} \mathrm{~cm}^{-3}$.

Embora apenas na densidade de $1,4 \mathrm{~g} \mathrm{~cm}^{-3}$ tenha havido efeito significativo da presença do herbicida na área foliar da soja, há tendência de que o herbicida reduza essa variável (Tabela 3). Esse fato se acentua à medida que aumenta a densidade, provavelmente devido ao acúmulo do herbicida na superficie do solo, em virtude da restrição na sua percolação e conseqüente aumento da concentração disponivel para absorção radicular pela cultura.

Os sintomas de fitointoxicação do sulfentrazone são originados a partir da inibição da ação da enzima Protox, a última enzima 
comum tanto à sintese da clorofila como do grupo heme, que inibe a transformação do protoporfirogênio para protoporfirina (Duke et al., 1991; Lee et al., 1993), ocorrendo a oxidação citossólica do protoporfirogênio, com o conseqüente acúmulo de protoporfirina. Este composto, em tecidos iluminados e na presença do $\mathrm{O}_{2}$, ocasiona a formação de oxigênio singlet, o qual, agindo como radical livre, provoca a peroxidação dos lipídios das membranas celulares em plantas ou tecidos sensiveis, com conseqüente morte celular (Lee et al., 1993; Dayan \& Weete, 1996; Hulting et al., 2001). A clorose é ocasionada pelo bloqueio da sintese de clorofila (Duke et al., 1991; Dayan \& Weete, 1996). A injúria na parte aérea das plantas expostas ao sulfentrazone parece ser facilitada pelo rápido transporte e acúmulo do herbicida nas folhas, onde é o seu local de ação - mais especificamente, o envelope do cloroplasto (Duke et al., 1991; Lee et al., 1993).

Com o aumento da densidade do solo, ocorre diminuição da área foliar, e essa diminuição é mais pronunciada na presença do sulfentrazone, demonstrando a potencialização do efeito de fitointoxicação do herbicida para a soja nessas condições (Figura 1). Houve pequeno incremento na área foliar, à medida que a densidade do solo aumentou até $1,13 \mathrm{~g} \mathrm{~cm}^{-3}$, tanto para o tratamento com herbicida quanto para aquele sem herbicida, indicando que o aumento de densidade do solo, a partir desse nivel, passou a afetar a área foliar da soja. É possivel observar ainda que na presença do sulfentrazone houve redução mais acentuada da área foliar, quando comparado à ausência do herbicida. Swantek et al. (1998) avaliaram as injúrias causadas pelo sulfentrazone em variedades de soja suscetível e tolerante e constataram diminuição da área foliar na presença do herbicida na soja suscetível, enquanto a soja tolerante não demonstrou diminuição da sua área foliar. Esse fato indica que a área foliar pode se constituir num indicador na avaliação da sensibilidade de espécies suscetiveis ou tolerantes ao sulfentrazone.

Oliveira Jr. et al. (2004), com uma metodologia semelhante à utilizada neste trabalho, observaram que os herbicidas imazaquin+trifuralin, aplicados em diferentes doses em solos compactados, apresentaram maior efeito tóxico à medida que a compactação do solo aumentou. A cultura da soja apresentou menor massa seca da parte aérea e de raízes à medida que se aumentaram a densidade do solo e a dose aplicada desses herbicidas. De forma semelhante, os resultados obtidos para área foliar neste trabalho indicam que a compactação do solo pode ser também fator importante no aumento da sensibilidade da soja ao sulfentrazone.

Tabela 2 - Área foliar $\left(\mathrm{cm}^{2}\right.$ planta-1) de plantas de soja, cv. BRS-133, em função da densidade do solo e da fração de poros com água

\begin{tabular}{|c|c|c|c|c|}
\hline \multirow{2}{*}{$\begin{array}{c}\text { Fração de poros } \\
\text { com água (Fpa) }\end{array}$} & 1,0 & 1,2 & 1,4 & 1,5 \\
\cline { 2 - 5 } & $448,51 \mathrm{Aa}$ & $492,16 \mathrm{Aa}$ & $294,07 \mathrm{Ab}$ & $93,94 \mathrm{Ac}$ \\
\hline Fpa $70 \%$ & $464,63 \mathrm{Ab}$ & $527,34 \mathrm{Aa}$ & $229,68 \mathrm{Bc}$ & $70,11 \mathrm{Ad}$ \\
\hline Fpa $80 \%$ & &
\end{tabular}

Médias seguidas pela mesma letra, maiúscula na coluna e minúscula na linha, não apresentam diferenças estatísticas significativas pelo teste de Tukey a $5 \%$.

Tabela 3 - Área foliar $\left(\mathrm{cm}^{2}\right.$ planta $\left.{ }^{-1}\right)$ de plantas de soja, cv. BRS-133, em função da densidade do solo, na presença ou ausência do herbicida sulfentrazone

\begin{tabular}{|l|c|c|c|c|}
\hline \multirow{2}{*}{\multicolumn{1}{|c|}{ Herbicida }} & \multicolumn{4}{|c|}{ Densidade do solo $\left(\mathrm{g} \mathrm{cm}^{-3}\right)$} \\
\cline { 2 - 5 } & 1,0 & 1,2 & 1,4 & 1,5 \\
\hline Com herbicida & $438,55 \mathrm{Ab}$ & $498,47 \mathrm{Aa}$ & $228,30 \mathrm{Bc}$ & $76,47 \mathrm{Ad}$ \\
\hline Sem herbicida & $474,60 \mathrm{Aa}$ & $520,02 \mathrm{Aa}$ & $295,45 \mathrm{Ab}$ & $87,58 \mathrm{Ac}$ \\
\hline
\end{tabular}

Médias seguidas pela mesma letra, maiúscula na coluna e minúscula na linha, não apresentam diferenças estatísticas significativas pelo teste de Tukey a $5 \%$. 


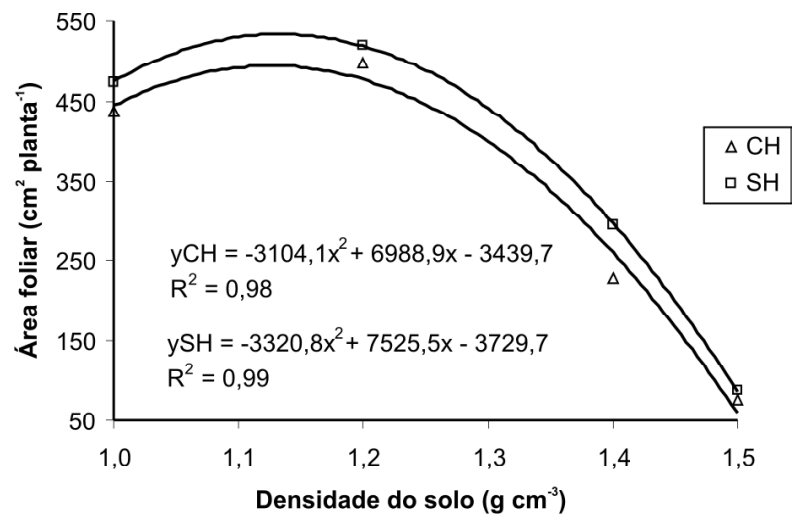

Figura 1 - Área foliar $\left(\mathrm{cm}^{2}\right.$ planta $\left.^{-1}\right)$ de plantas de soja, cv. BRS-133, em função da densidade do solo, na presença $(\Delta)$ ou ausência ( $\square$ ) do sulfentrazone.

\section{Número de nódulos}

Segundo Hungria et al. (2001), uma planta de soja bem nodulada no campo, na época do florescimento, apresenta em torno de 15 e 30 nódulos ou 100 a $200 \mathrm{mg}$ de nódulos secos por planta. Adotando-se esse referencial, apenas plantas cultivadas em densidades menores ou iguais a $1,2 \mathrm{~g} \mathrm{~cm}^{-3}$ teriam se aproximado de uma nodulação adequada (Tabela 4).

Avaliando o efeito da interação entre compactação e herbicida no número de nódulos, observa-se na Tabela 4 a diminuição do número de nódulos por planta na densidade de $1,2 \mathrm{~g} \mathrm{~cm}^{-3}$ quando se utilizou o sulfentrazone.

$\mathrm{Na}$ Figura 2, observa-se que, com o aumento da densidade do solo, ocorre também diminuição do número de nódulos, a qual é mais acentuada na presença do sulfentrazone, possivelmente devido à potencialização da toxicidade do herbicida em virtude da limitação na sua lixiviação.

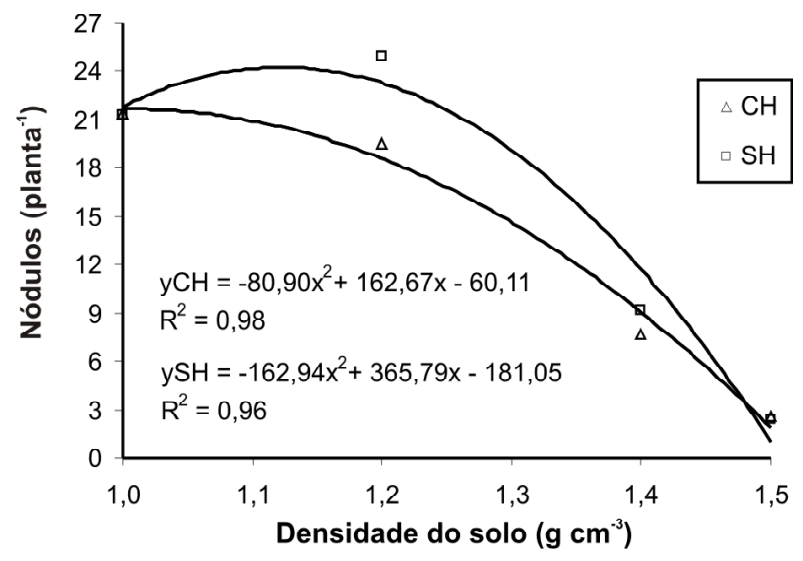

Figura 2 - Número de nódulos por plantas de soja, cv. BRS133, em função da densidade do solo, na presença $(\Delta)$ ou ausência $(\square)$ do sulfentrazone.

Dentro do intervalo de densidades avaliado, ocorreu pequeno incremento inicial no número de nódulos das plantas de soja com o aumento da densidade do solo na ausência do sulfentrazone, uma vez que o ponto de máximo da curva ajustada foi na densidade de $1,12 \mathrm{~g} \mathrm{~cm}^{-3}$ (SH). Esse fato indica que o aumento de densidade do solo, a partir desse nível, passa a comprometer o número de nódulos na planta. $\mathrm{Na}$ presença do sulfentrazone, o número de nódulos por planta foi continuamente reduzido com o aumento da densidade do solo. Arruda et al. (2001), estudando a nodulação e a fixação do nitrogênio em soja tratada com sulfentrazone, também observaram redução significativa do número de nódulos em razão do aumento de doses do sulfentrazone.

Em relação ao efeito da fração de poros com água (Fpa, Tabela 5), observa-se redução de $21,8 \%$ no número de nódulos para $\mathrm{Fpa} 80 \%$, ao passo que não houve diferenças para Fpa $70 \%$, sugerindo que a disponibilidade de água

Tabela 4 - Número de nódulos de plantas de soja, cv. BRS-133, em função da densidade do solo, na presença ou ausência do herbicida sulfentrazone

\begin{tabular}{|l|c|c|c|c|}
\hline \multirow{2}{*}{\multicolumn{1}{c|}{ Herbicida }} & \multicolumn{4}{|c|}{ Densidade do solo $\left(\mathrm{g} \mathrm{cm}^{-3}\right)$} \\
\cline { 2 - 5 } & 1,0 & 1,2 & 1,4 & 1,5 \\
\hline Com herbicida & $21,37 \mathrm{Aa}$ & $19,50 \mathrm{Ba}$ & $7,66 \mathrm{Ab}$ & $2,58 \mathrm{Ac}$ \\
\hline Sem herbicida & $21,29 \mathrm{Aa}$ & $24,95 \mathrm{Aa}$ & $9,16 \mathrm{Ab}$ & $2,37 \mathrm{Ac}$ \\
\hline
\end{tabular}

Médias seguidas pela mesma letra, maiúscula na coluna e minúscula na linha, não apresentam diferenças estatísticas significativas pelo teste de Tukey a $5 \%$. 
pode ter facilitado a chegada do herbicida ao sistema radicular, aumentando a intensidade de absorção do produto.

\section{Massa seca dos nódulos}

Observa-se na Tabela 6 que, na presença do sulfentrazone, a massa seca dos nódulos é reduzida em 13,7 e 41,7\% para as densidades de 1,0 e $1,4 \mathrm{~g} \mathrm{~cm}^{-3}$, respectivamente, evidenciando que o sulfentrazone causou efeito negativo na população de bactérias simbióticas. Esse efeito pode ser atribuído à compactação do solo, que causou limitação do volume de solo explorável pelo sistema radicular, resultando em maior predisposição das raízes e nódulos de se desenvolverem nas camadas superficiais com maiores concentrações do sulfentrazone. Segundo Hulting et al. (2001), solos compactados e úmidos aumentam o tempo de exposição da planta ao sulfentrazone no solo, contribuindo para maiores injúrias.

Com o aumento da densidade do solo, ocorre diminuição da massa seca dos nódulos, a qual é mais acentuada na presença do sulfentrazone (Figura 3). A redução da massa seca dos nódulos pode ter sido causada de forma indireta, pelo efeito fitotóxico do herbicida, acarretando menor produção e menor quantidade de fotoassimilados translocados e alocados aos nódulos, pois o fornecimento de fotoassimilados é essencial à formação e à manutenção da atividade da enzima nitrogenase presente nos nódulos (Arruda et al., 2001).

Da mesma forma, houve discreto incremento inicial na massa seca desses nódulos com o aumento da densidade do solo, cujos pontos de máximo das curvas ajustadas foram nas densidades de $1,02(\mathrm{CH})$ e $1,09 \mathrm{~g} \mathrm{~cm}^{-3}(\mathrm{SH})$, indicando que o aumento de densidade do solo, a partir desses niveis, causou diminuição da massa seca dos nódulos, além do fato de que a diminuição foi mais acentuada na presença do sulfentrazone (Figura 3).

Comparando-se a variação de Fpa e da densidade do solo, o efeito desta foi o fator mais drástico na redução da massa seca dos nódulos, com diminuição de 93\% na presença do sulfentrazone e de $90 \%$ na sua ausência.

\section{Acúmulo de nitrogênio}

Os resultados anteriores demonstraram que houve diminuição do número de nódulos e também da massa seca destes na presença do sulfentrazone. Os dados da Tabela 7 evidenciam que esse efeito também foi observado para acúmulo de nitrogênio nas plantas, sendo essa redução significativa nas densidades de 1,0 e $1,2 \mathrm{~g} \mathrm{~cm}^{-3}$. Nas densidades maiores, o efeito mais pronunciado que influenciou o

Tabela 5 - Número de nódulos por plantas de soja, cv. BRS-133, em função da presença ou ausência do herbicida sulfentrazone na fração de poros com água

\begin{tabular}{|l|c|c|}
\hline \multirow{2}{*}{$\begin{array}{c}\text { Fração de Poros com Água } \\
\text { (Fpa) }\end{array}$} & \multicolumn{2}{|c|}{ Herbicida } \\
\cline { 2 - 3 } & Sem herbicida & Com herbicida \\
\hline Fpa $_{70 \%}$ & $12,37 \mathrm{Ba}$ & $12,64 \mathrm{Aa}$ \\
\hline $\mathrm{Fpa}_{80 \%}$ & $16,52 \mathrm{Aa}$ & $12,91 \mathrm{Ab}$ \\
\hline
\end{tabular}

Médias seguidas pela mesma letra, maiúscula na coluna e minúscula na linha, não apresentam diferenças estatísticas significativas pelo teste de Tukey a $5 \%$.

Tabela 6 - Massa seca dos nódulos (mg planta-1 $)$ de plantas de soja, cv. BRS-133, em função da densidade do solo, na presença ou ausência do herbicida sulfentrazone

\begin{tabular}{|l|c|c|c|c|}
\hline \multirow{2}{*}{ Herbicida } & \multicolumn{4}{|c|}{ Densidade do solo $\left(\mathrm{g} \mathrm{cm}^{-3}\right)$} \\
\cline { 2 - 5 } & 1,0 & 1,2 & 1,4 & 1,5 \\
\hline Com herbicida & $233 \mathrm{Ba}$ & $250 \mathrm{Aa}$ & $77 \mathrm{Bb}$ & $17 \mathrm{Ac}$ \\
\hline Sem herbicida & $270 \mathrm{Aa}$ & $268 \mathrm{Aa}$ & $132 \mathrm{Ab}$ & $28 \mathrm{Ac}$ \\
\hline
\end{tabular}

Médias seguidas pela mesma letra, maiúscula na coluna e minúscula na linha, não apresentam diferenças estatísticas significativas pelo teste de Tukey a $5 \%$. 
Tabela 7 - Acúmulo de nitrogênio (mg planta ${ }^{-1}$ ) de plantas de soja, cv. BRS-133, em função da densidade do solo, na presença ou ausência do herbicida sulfentrazone

\begin{tabular}{|l|c|c|c|c|}
\hline \multirow{2}{*}{ Herbicida } & \multicolumn{4}{|c|}{ Densidade do solo $\left(\mathrm{g} \mathrm{cm}^{-3}\right)$} \\
\cline { 2 - 5 } & 1,0 & 1,2 & 1,4 & 1,5 \\
\hline Com herbicida & $92,12 \mathrm{Ba}$ & $100,61 \mathrm{Ba}$ & $53,52 \mathrm{Ab}$ & $17,88 \mathrm{Ac}$ \\
\hline Sem herbicida & $105,19 \mathrm{Aa}$ & $116,40 \mathrm{Aa}$ & $63,23 \mathrm{Ab}$ & $18,50 \mathrm{Ac}$ \\
\hline
\end{tabular}

Médias seguidas pela mesma letra, maiúscula na coluna e minúscula na linha, não apresentam diferenças estatísticas significativas pelo teste de Tukey a $5 \%$.

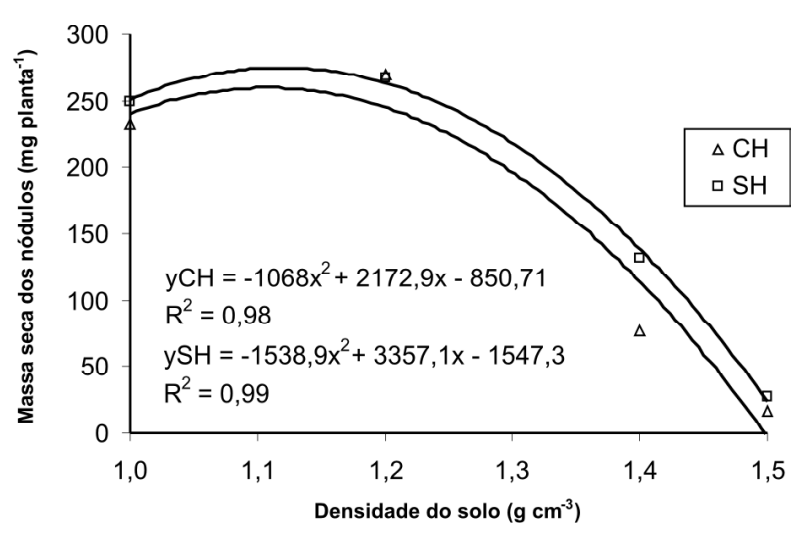

Figura 3 - Massa seca dos nódulos de plantas de soja, cv. BRS-133, em função da densidade do solo na presença $(\Delta)$ ou ausência ( $\square$ ) do sulfentrazone.

acúmulo de $\mathrm{N}$ parece ter sido a compactação do solo, uma vez que o efeito da presença do sulfentrazone passa a ser não-significativo.

Na Figura 4, observa-se tendência de diminuição do acúmulo de nitrogênio quando se aumenta a compactação do solo, sendo essa diminuição mais acentuada na presença do sulfentrazone, evidenciando a potencialização do efeito tóxico do herbicida à cultura em solos compactados.

Da mesma forma que houve pequeno incremento no número de nódulos com o aumento da densidade do solo, ocorreu também pequeno incremento no acúmulo de nitrogênio das plantas de soja com o aumento da densidade, pois o ponto de máximo da curva ajustada ocorreu na densidade de $1,13 \mathrm{~g} \mathrm{~cm}^{-3}(\mathrm{SH})$,

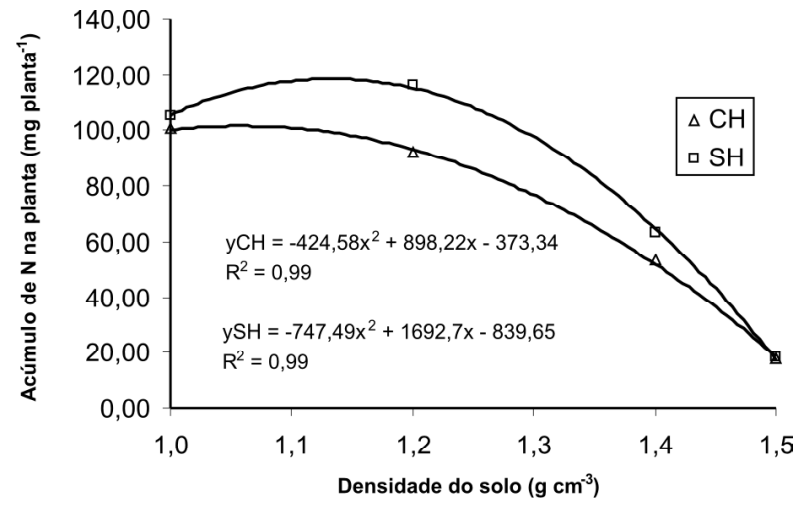

Figura 4 - Acúmulo de nitrogênio $\left(\mathrm{mg} \mathrm{planta}^{-1}\right)$ na parte aérea de plantas de soja, cv. BRS-133, em função da densidade do solo na presença $(\Delta)$ ou ausência $(\square)$ do sulfentrazone.

indicando que o aumento de densidade do solo, a partir desse nivel, passa a comprometer o acúmulo de nitrogênio na planta. Essa diminuição é mais acentuada na presença do sulfentrazone, que mostrou ponto de máximo em $1,05 \mathrm{~g} \mathrm{~cm}^{-3}(\mathrm{CH})$, ou seja, na presença do sulfentrazone houve inibição do acúmulo de nitrogênio mesmo sob condições normais de densidade do solo.

Em resumo, o sulfentrazone reduziu a área foliar, a formação de nódulos, a massa seca dos nódulos e o acúmulo de $\mathrm{N}_{2}$ na parte aérea de plantas de soja, sendo esses efeitos mais acentuados com o aumento da densidade do solo. O aumento da densidade do solo afetou as variáveis relacionadas à cultura de modo mais acentuado do que a presença do sulfentrazone. 


\section{LITERATURA CITADA}

ALVES, P. L. C. A.; JUNIOR, J. M.; FERRAUDO, A. S. Soil attributes and the efficiency of sulfentrazone on control of purple nustedge (Cyperus rotundus L.). Sci. Agric., v. 61, n. 3, p. 319-325, 2004.

ARRUDA, J. S.; LOPES, N. F.; BACARIN, M. A. Nodulação e fixação do dinitrogênio em soja tratada com sulfentrazone. Pesq. Agropec. Bras., v. 36, n. 2, p. 325-330, 2001.

DAYAN, F. E.; WEETE, J. D. Mechanism of tolerance to a novel phenyl triazolinone herbicide. Plant Physiol., p. 111119, 1996.

DAYAN, F. E. et al. Soybean (Glycine max) cultivar differences in response to sulfentrazone. Weed Sci., v. 45, p. $634-641,1997$.

DIRKS, J. T. et al. Reduced rates of sulfentrazone plus chlorimuron and glyphosate in no-till, narrow-row, ghyphosate-resistant Glycine $\max$. Weed Sci., v. 48, p. 618$627,2000$.

DUKE, S. O. et al. Protoporphyrinogen oxidase-inhibiting herbicides. Weed Sci., v. 39, p. 465-473, 1991.

GOEDERT, W. J.; SCHERMACK, M. J.; DE FREITAS, F. C. Estado de compactação do solo em áreas cultivadas no sistema de plantio direto. Pesq. Agropec. Bras., v. 37 , p. 223-227, 2002.

GREY, T. L. et al. Behavior of sulfentrazone in ionic exchange resins, electrophoresis gels, and cation-saturated soils. Weed Sci., v. 48, p. 239-247, 2000.

GREY, T. L. et al. Sulfentrazone adsorption and mobility as affected by soil and pH. Weed Sci., v. 45, p. 733-738, 1997.

GUSTAFSON, D. I. Groundwater ubiquity score: a simple method for assessing pesticide leachability. Environ.

Toxicol. Chem., v. 8, p. 339-357, 1989.

HULTING, A. G. et al. Soybean (Glycine $\max$ (L.) Merr.) cultivars tolerance to sulfentrazone. Crop Protec., v. 20, p. 679-683, 2001.

HUNGRIA, M.; CAMPO, R. J.; MENDES, I. C. Fixação biológica do nitrogênio na cultura da soja. Brasília: Embrapa Cerrados, 2001. 48 p. (Circular Técnica, 13).

INOUE, M. H. et al. Critérios para avaliação do potencial de lixiviação dos herbicidas comercializados no Estado do Paraná. Planta Daninha, v. 21, n. 2, p. 313-323, 2003.

LEE, H. J.; DUKE, S. O.; DUKE, M. V. Cellular localization of protoporphyrinogen-oxidizing activities of etiolated barley (Hordeum vulgare L.) leaves. Plant Physiol., v. 102, p. 881-889, 1993.
MUELLER, M.M.L.; CECCON, G.; ROSOLEM, C.A. Influência da compactação do solo em subsuperfície sobre o crescimento aéreo e radicular de plantas de adubação verde de inverno. R. Bras. Ci. Solo, v. 25, n. 3, p. 531-538, 2001.

OLIVEIRA Jr., R. S. et al. Compactação do solo afeta a fitotoxicidade de herbicidas. In: CONGRESSO BRASILEIRO DE CIÊNCIA DAS PLANTAS DANINHAS, 24., 2004, São Paulo. Anais... São Pedro: Sociedade Brasileira da Ciência das Plantas Daninhas, 2004. CD ROM

PREVEDELLO, C. L. Física do solo com problemas resolvidos. Curitiba: $1996.446 \mathrm{p}$.

PROCÓPIO, S. O. et al. Características fisiológicas das culturas de soja e feijão e de três espécies de plantas daninhas. Planta Daninha, v. 22, n. 2, p. 211-216, 2004.

QUEIROZ-VOLTAN, R. B.; NOGUEIRA, S. S. S.; MIRANDA, A. C. Aspectos da estrutura da raiz e do desenvolvimento de plantas de soja em solos compactados. Pesq. Agropec. Bras., v. 35, n. 5, p. 929-938, 2000.

REDDY, K. N.; LOCKE, M. A. Sulfentrazone sorption, desorption, and mineralization in soils from two tillage systems. Weed Sci., v. 46, p. 494-500, 1998.

SPADOTTO, C. A. Screening method for assessing pesticide leaching potential. Pesticidas: R. Ecotoxicol. Meio Amb., v. 12, p. 69-78, 2002.

SIDIRAS, N.; VIEIRA, M. J. Comportamento de um latossolo roxo distrófico, compactado pelas rodas do trator na semeadura. Pesq. Agrop. Bras., v. 19, p. 1285-1293, 1984.

STONE, L. F.; GUIMARÃES, C. M.; MOREIRA, J. A. A. Compactação do solo na cultura do feijoeiro. I. efeitos nas propriedades físico-hídricas do solo. R. Bras. Eng. Agric. Amb., v. 6, n. 2, p. 207-212, 2002.

SWANTEK, J. M.; SNELLER, C. H.; OLIVER, L. R. Evaluation of soybean injury from sulfentrazone and inheritance of tolerance. Weed Sci., v. 46, p. 271-277, 1998.

TORMENA, C. A. et al. Densidade, porosidade e resistência à penetração em latossolo cultivado sob diferentes sistemas de preparo do solo. Sci. Agric., v. 59, n. 4, p. 795-801, 2002.

VELINI, E. D. Comportamento de herbicida no solo. In: SIMPÓSIO NACIONAL SOBRE MANEJO DE PLANTAS DANINHAS EM HORTALIÇAS, 1992, Botucatu. 1992. Resumos... Botucatu: 1992. p. 44-64. 